\title{
POLITICAL AND SOCIOECONOMIC INFLUENCES ON SOCIAL DISTANCING BEHAVIOUR IN THE UNITED STATES
}

Liam Keating ${ }^{1}$, Nayan Saxena ${ }^{1}$, Emma Cooper ${ }^{2}$, Jordan Tirico ${ }^{3}$, Daniel Khain 4 \& Daphne Imahori ${ }^{1}$

\section{CONTENTS}

1 Introduction 2

2 Hypotheses 3

3 Methods 4

4 Results 5

4.1 Case Studies . . . . . . . . . . . . . . . . . 9

5 Discussion 12

6 Conclusions 13

7 Acknowledgements $\quad 13$

8 References 14

9 About the Student Authors $\quad 16$

10 Press Summary 16

11 Appendix 16

11.1 Graphs of Predicted SDI (VAR Models) . . . . . . . . . . . . . . 16

11.2 Model Diagnostic Plot . . . . . . . . . . . . . . 18

\begin{abstract}
The Social Distancing Index (SDI) measures social distancing behaviour every day across all fifty American states. This study leverages SDI data to model social distancing behaviour with time-series COVID-19 data, as well as an array of political and economic variables. The central aim of this study is to examine three hypotheses: (i) COVID-19 outbreaks within a state will induce social distancing by fear of the virus, (ii) states with more low-income workers will engage in less social distancing due to the nature of essential work, and (iii) political beliefs will influence social distancing behaviour, through the public debate over social distancing policy and a partisan logic defining state stay-at-home orders. We use Vector Autoregressive (VAR) and Beta Regression models to determine the most influential variables in this study. VAR models for time-series relationships between cases and social distancing behaviour in California and Texas, and corresponding Granger-Cause Test results, are investigated through case studies. Significant Beta model variables influencing social distancing behaviour are closely examined through visual data analysis and qualitatively contextualized to describe relationships present in the data. Our results indicate statistically significant relationships between the severity of state outbreaks, age and income distribution, change in governor approval ratings, and social distancing behaviour. There are also clear relationships between the partisan make-up of a state and social distancing behaviour. The results found in this study contribute to growing evidence regarding the impact political polarization has on various aspects of American social life, while giving insight to behavioural dynamics that play a critical role in mitigating the spread of COVID-19.
\end{abstract}

Keywords: COVID-19; Social Distancing; Public Health Behaviour; Political Polarization; Political Science; Public Health; Sociology; Income

\footnotetext{
${ }^{1}$ University of Toronto

2 University of California, Berkeley

3 Stanford University

4 University of Michigan
} 
As COVID-19 swept through the United States in March 2020, a debate formed over the question of social distancing policy. Should governors order the shutdown of their state's non-essential businesses, urging constituents to stay inside? Or should states remain open to avoid an economic shock? The trade-off described by some prominent public officials in this debate essentially boiled down to two options: save the economy, or save people from COVID-19.

Texas Lieutenant Governor Dan Patrick described this decision framework bluntly. Patrick claimed on March 23 that he would be willing to "take a chance on [his] survival" in order to "keep the America that all America loves" for his grandchildren, adding that he believes there are "a lot of grandparents out there in this country like me" (Beckett, 2020). The Lieutenant Governor was echoing a sentiment shared by President Donald Trump the day before on Twitter: "WE CANNOT LET THE CURE BE WORSE THAN THE PROBLEM ITSELF." The President vowed in the same statement to reassess social distancing recommendations after the CDC's initial 15-day guidelines expired on March 30 (Haberman and Sanger, 2020).

The Trump administration's own public health experts were quick to state that the fifteen-day period would probably be insufficient to slow the spread of COVID19. Dr. Anthony Fauci, Director of the National Institute of Allergy and Infectious Diseases at the CDC, warned on multiple occasions that a quick return to normal economic activity would risk worsening ongoing outbreaks while enabling new ones (Baker, 2020). This and other discord between the administration and the federal government's public health experts was made clear at daily press conferences held by the White House Coronavirus Task Force in April; something verging between cordiality and open feud has defined the President and Dr. Fauci's public relationship (Cathey, 2020).

Chaos in the American bureaucracy did not guarantee the United States would come to experience the worst of COVID-19's global devastation. Countries with federal systems of government and strong states have been able to use the flexibility offered by subnational authority to their advantage; perhaps most notably Germany, where state governments allowed for effective locally-specific responses (Wong, 2020). While in Germany, reliance on state governments was an efficient choice and federal involvement was met with criticism (Johnson, 2020), American states took a central role by necessity, in the absence of federal leadership.

This leadership crisis began before COVID-19 was transmitted to humans, in the never-ending pandemic phase: preparation. Experts repeatedly raised alarms as the President dismantled the CDC's global monitor-and-response network for infectious diseases (Belluz, 2018) and disbanded the National Security Council's pandemic response team (Reuters, 2020). The administration also drew harsh criticism for consistently refusing to effectively invoke the Defense Production Act, which could be used to stabilize supply chains for scarce medical supplies (Kavi, 2020).

Meanwhile, administration officials interfered with the CDC's already limited capacity, editing official social distancing recommendations line-by-line at the behest of public health experts (Ballhaus et. al, 2020). These actions, paired with chronic federal inaction in PPE acquisition (Nguyen, 2020), left states alone to respond to the pandemic - and to determine the best implementation of social distancing policy.

Hindered by political polarization, however, was the independence of state governments to make their own decisions on social distancing. State social distancing policies were defined by a stark partisan logic. Republican governors acted significantly later than Democrats to implement social distancing policy by stay-at-home order, and were 60 per cent less likely to implement an order when controlling for pandemic and economic variables (Baccini \& Brodeur, 2020).

Social distancing is a behaviour. Individuals decide every day whether or not to buy into social distancing policies - to visit friends, gather in public spaces, 
attend restaurants, or stay home. Essential workers face a more difficult choice maintain a source of income and go to work, putting oneself at risk of COVID-19, or risk unemployment by requesting a furlough.

The politicization of social distancing is only part of a complex decision-making process engaged with every day by every American. The outcome of this decisionmaking process at a population level has been measured by the University of Maryland's Social Distancing Index (SDI), which analyzes cell phone geolocation data to produce an index of social distancing behaviour across states and counties. This study seeks to identify what influences social distancing behaviour by modeling SDI data, using a cross-section of variables built from three hypotheses.

\section{HYPOTHESES}

\section{THE “FEAR" hYPOTHESIS}

It is reasonable to argue that fear has the power to influence daily decision making in times of national crisis. After September 11th, an immediate decline in consumer spending (Perry, 2001) coincided with widespread public fear of falling victim to terrorism (Mueller, 2012). The public safety risk posed by COVID-19 in the United States between January and July 2020 was undoubtedly higher than that of terrorism in October 2001. And because the pandemic threat level can be constantly monitored - daily reports are available to anyone with Internet access - people in states with worse COVID-19 outbreaks may social distance more often.

Another way to measure fear's impact on social distancing behaviour centers on a state's proportion of residents in different age groups. Considering the higher risk of dying from COVID-19 complications faced by older adults, if fear is important to social distancing behaviour, states with larger populations of senior citizens will social distance more often. The "fear" hypothesis predicts that states with more cases and deaths, and with higher shares of senior citizens, will be more likely to social distance.

\section{THE “INCOME” HYPOTHESIS}

Income may influence social distancing behaviour due to the nature of essential labor. Many essential workers, such as grocery store clerks, gas station attendants, and food processing plant employees, are paid less than non-essential workers and are required to work in person (Nunn et. al, 2020). Those who hold higher-income positions deemed as non-essential, such as professors, lawyers, and management consultants, are able to work from home. As such, the "income" hypothesis predicts that states with lower median incomes, and relatively more low-income residents, will be less likely to social distance.

\section{THE “PARTISAN" HYPOTHESIS}

The partisan logic that has defined the timing of state social distancing policies is not surprising, though it is strong. Political polarization between parties and within the public has become a central facet of American political life in the past three decades (Abramowitz, 2010). Social distancing behaviour offers an unprecedented litmus test for American political polarization. Do people act in concert with their political beliefs, even if it could mean risking their lives? To give insight to this question, the "partisan" hypothesis measures the influence of four variables: President Trump's 2016 electoral margin in a state $(+/-)$, the party of its governor, the number of votes cast for Trump in 2016 relative to its population, and the change in its governor's approval rating during COVID-19 (Q4 2019 -> July 2020). 


\section{METHODS}

This study examines social distancing behaviour as measured by the University of Maryland and Maryland Transportation Institute's Social Distancing Index (SDI) from January 1, 2020, to July 14, 2020 in the United States. The SDI is time-series data. Its formula measures cell phone geolocation data to produce an output that measures social distancing behaviour for every state, every day.

Each variable serves to inform a specific hypothesis with an evidentiary basis. The "fear" hypothesis is based on changes in economic behaviour due to perceived risk after the attacks of September 11th, predicated on the assumption that COVID19 poses a similarly widespread and potentially higher perceived risk. The "income" hypothesis centers on evidence that essential workers are paid less than nonessential workers, and the assumption that by definition essential workers perform their labor in-person. The "partisan" hypothesis comes from evidence of a partisan logic defining the relative likelihood and timing of state stay-at-home orders, seeking to investigate the impact of this trend on behaviour.

The "fear" hypothesis allows for use of the time-series data given by the SDI, because time-series data are available for reported cases and deaths on a daily basis for all states. We used the R covid19. analytics database (Ponce, 2020) to measure the daily reports of cases and deaths in each state during the January 1 - July 14 period of investigation.

For the states of Texas and California, Vector Autoregression models were fitted to perform Granger Causality tests to determine if the effect of daily cases on SDI time data within a given state is significant. Texas and California were selected for the daily caseload VAR models for two reasons - first, their populations are the largest in the US; second, partisan differences in policy stringency and rhetoric observed at the national level were mirrored in these states' responses. A table of results obtained for Texas and California can be seen below. See Appendix 8.1 for graphs of fitted models.

\begin{tabular}{l|r|r}
\hline & \multicolumn{2}{|c}{$\mathrm{p}$ Values From Granger Test } \\
\hline Null Hypothesis $\left(\mathrm{H}_{0}\right)$ & Texas & California \\
\hline Cases do not affect social distancing & 0.9818 & 0.007735 \\
\hline Social distancing does not affect cases & 0.01691 & 0.01764
\end{tabular}

Table 1: Hypothesis and $p$ values obtained using the Granger Causality Test for Texas and California

The data used to measure the "partisan" and "income" hypotheses are static in nature, as political beliefs and income data are less readily available and reliably measurable in a time-series format. To transform SDI data into a non-time series format that is both valid and useful for determining the influence of political beliefs and income on social distancing behaviour, we decided to take a mean of each state's SDI data from January 1 - July 14 . Taking the mean captures the totality of social distancing behaviour over the entire period of investigation, allowing for the assessment of pre-existing political beliefs, economic trends and their respective impacts.

Finally, using these variables we fitted a Beta Regression model with Social Distancing Index as the response variable for exploratory analysis across all states in the US. It should be noted that Social Distancing Index was divided by 100 to transform it into a statistic that lies in the interval $[0,1]$ thus making it an appropriate response variable for Beta Modelling. The fitted model yields the following summary table for coefficients which we will closely examine in the rest of our analyses. Furthermore, the proposed Beta Regression model is effective at explaining variation in average SDI across states which can be seen from the diagnostic plots (See Appendix 8.2). 


\begin{tabular}{|c|c|}
\hline Variables & $\operatorname{Pr}[>Z]$ \\
\hline Intercept & 0.718280 \\
\hline Total Deaths & 0.000000 \\
\hline Population Proportion of Votes for Trump (2016) & 0.1887560 \\
\hline Party of State Governor & 0.5486777 \\
\hline Trump Margin of Victory in 2016 & 0.1037308 \\
\hline Change in Governor Rating Pre to Post COVID-19 & 0.0157819 \\
\hline Proportion of Children o-18 & 0.0891021 \\
\hline Proportion of Adults 19-25 & 0.5979799 \\
\hline Proportion of Adults 26-34 & 0.1519752 \\
\hline Proportion of Adults $35-54$ & 0.0046459 \\
\hline Proportion of Adults $55-64$ & 0.3743111 \\
\hline Proportion of Adults $65^{+}$ & 0.0000629 \\
\hline Household Income Less Than 10,000\$ & 0.4739243 \\
\hline Household Income Less Than 10,000\$-14,999\$ & 0.0243091 \\
\hline Household Income Less Than 15,000\$-24,999\$ & 0.0322857 \\
\hline Household Income Less Than 25,000\$-34,999\$ & 0.5271765 \\
\hline Household Income Less Than 35,000\$-49,999\$ & 0.0767562 \\
\hline Household Income Less Than 50,000\$-74,999\$ & 0.3104461 \\
\hline Household Income Less Than 75,000\$-99,999\$ & 0.0545321 \\
\hline Household Income Less Than 100,000\$-149,999\$ & 0.5869812 \\
\hline Median Income & 0.2054839 \\
\hline
\end{tabular}

Table 2: Table of Variables and Coefficient $p$ values for fitted Beta Regression Model

\section{RESULTS}

\section{THE “FEAR" HYPOTHESIS}

Total deaths in a state had the most significant influence on social distancing behaviour out of all variables in the fitted statistical model (Table 2). States that experienced more deaths from COVID-19 tended to social distance more during the period of investigation. In the initial days of the pandemic, as New York City hospitals were overwhelmed and universities prepared to contain excess patients in empty dorms, most states saw high levels of social distancing. There is a notable spike in social distancing behaviour across the country on and after March 13th, the day that President Trump issued a proclamation declaring a national emergency concerning COVID-19 (Figure 1).

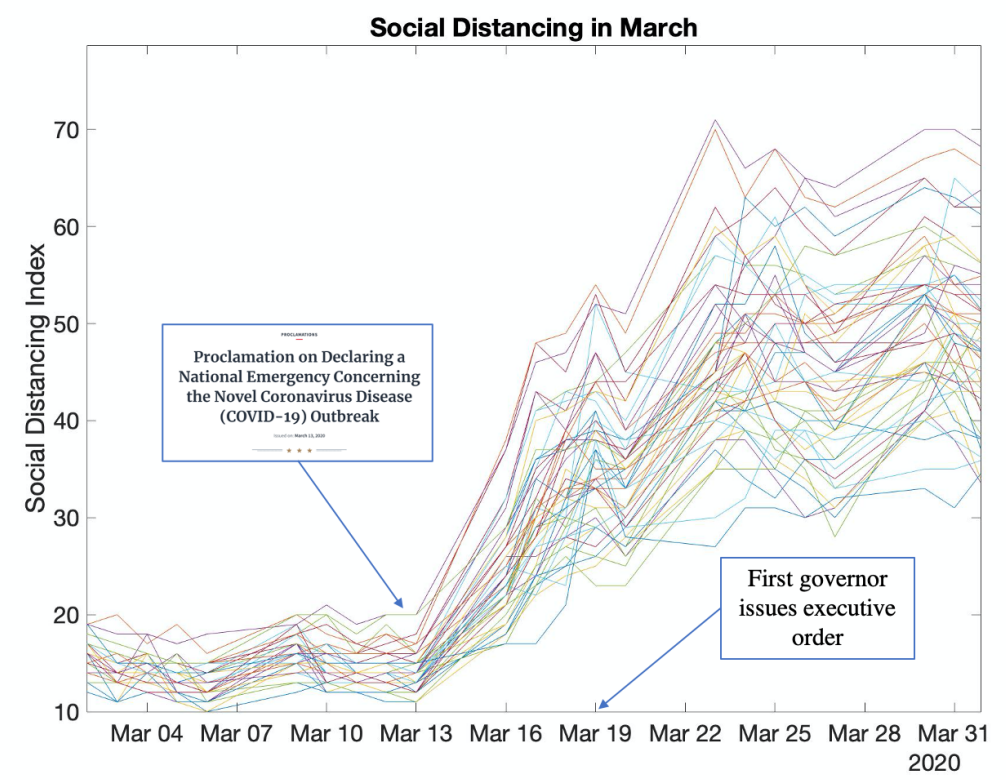

Figure 1: Graph of social distancing index during the month of March for various states across the United States

Much of the variation in social distancing behaviour has occurred since the week immediately following the March 13 proclamation, as fear of the virus may have become more abstract in the minds of Americans yet to be impacted. But for those still 
in New York City, Detroit, New Jersey, Baton Rouge or Connecticut, the constant threat posed by proximate social interaction could not be forgotten; tens or hundreds of lives were lost each day. As the virus spread to new hotspots, like Houston, Phoenix, Miami-Dade county, and Los Angeles, social distancing behaviour followed.

Texas is a good example of this trend. Social distancing behaviour steadily declined in May under relaxed restrictions, even as cases continued to rise in the state. But as deaths quickly climbed in mid-to-late June, social distancing slowly followed. This suggests that the urgency of fear regarding COVID-19 is important. The risk of worsening budding outbreaks by failing to social distance does not appear to have a consistent effect on behaviour: as shown by the Granger Causality Test, more cases did not lead to more social distancing behaviour in Texas (Table 1). The uptick in social distancing behaviour observed after deaths began to rise in Texas in mid-June is a case-in-point example of the most significant trend observed nationally: the perceived threat of dying from COVID-19 has a powerful impact on behaviour (Figure 2).

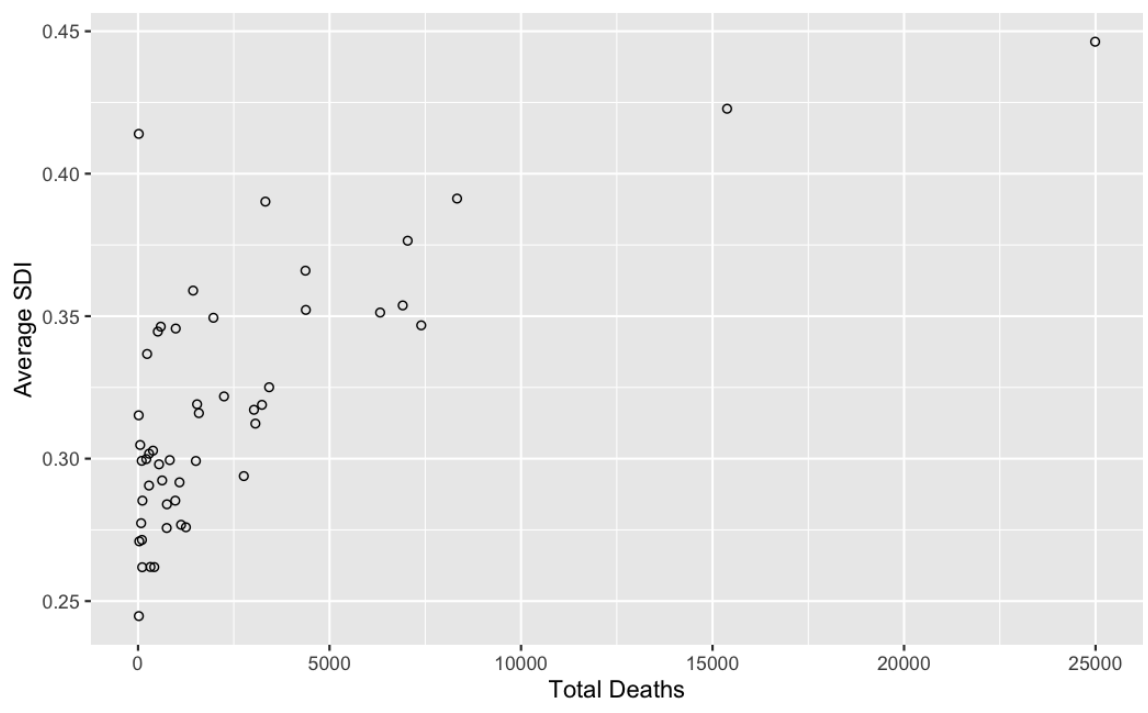

Figure 2: Scatterplot of Deaths and Average SDI for every state in the United States

Further evidence for the "fear" hypothesis comes from a concentrated fear experienced by senior citizens during COVID-19. This is due to well-publicized research demonstrating higher rates of hospitalization and death for older adults (CDC, 2020). Old age has a significant impact on social distancing behaviour - states with a higher proportion of Americans over the age of 65 typically engage in more social distancing. These two independent variables, total deaths and proportion of residents older than 65 , show the highest Beta coefficients among all variables, giving credence to the fear hypothesis.

\section{THE “INCOME” HYPOTHESIS}

The model pointed to four income variables with statistically significant impacts on social distancing behaviour, out of eight brackets of income distribution data tested. These relationships are described in Figure 2 below. The first three (Figure $3 a, b$ \& $)$ of these figures show a strong negative relationship between the significant brackets and mean social distancing as denoted by the fitted lines.

As shown, states with a higher proportion of residents in the two lowest income brackets (Figures 3a \& b), and in the fourth lowest income bracket (Figure 3c), engaged in less social distancing. This is in line with the "essential work" causal mechanism, as lower-income workers are disproportionately considered essential (Nunn et. al, 2020). Therefore, states with a higher proportion of low-income jobs would have a higher proportion of essential workers, resulting in less social distancing. The statistical significance of these three results offers empirical evidence to this argument. 


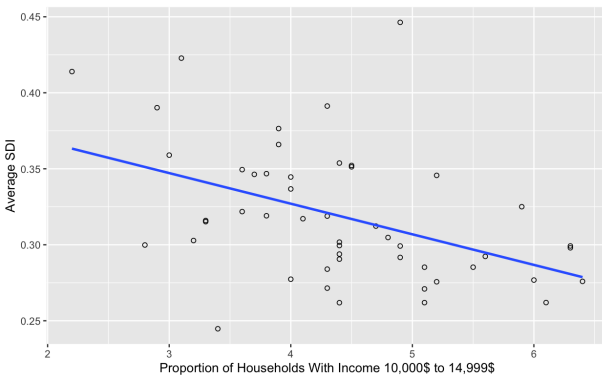

(a)

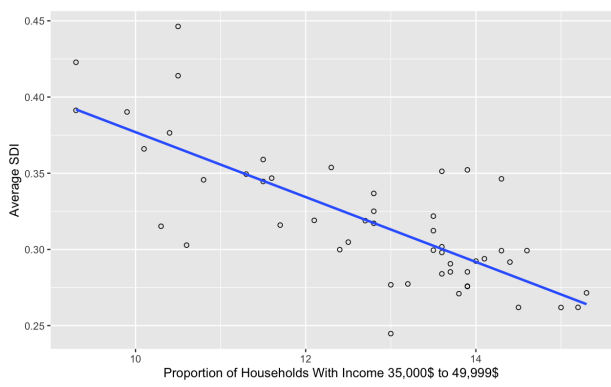

(c)

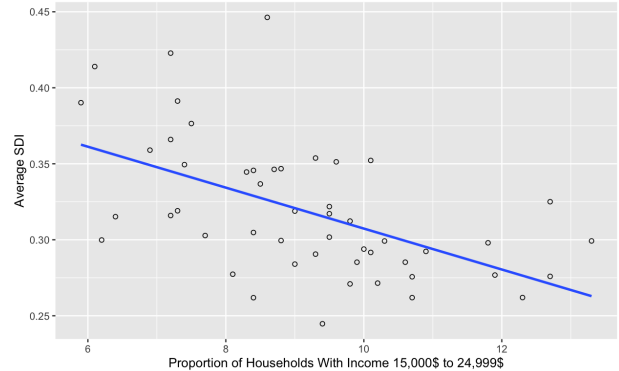

(b)

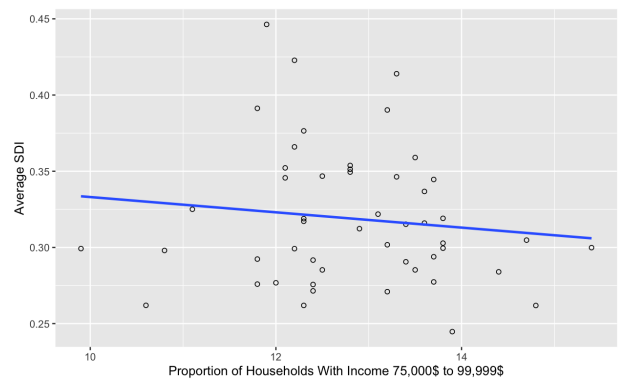

(d)

Figure 3: Relationship between statistically significant income brackets and average SDI for various states in the Unied States. The blue line indicates nature of the relationship which is negative in all examples.

While not statistically significant, the relationship between median income and social distancing behaviour is consistent with the low to low-middle income population brackets. States with higher median incomes social distanced more often than states with lower incomes (Figure 4). Just as low-income work is disproportionately essential and in-person, high-income work may be more adaptable to an online setting.

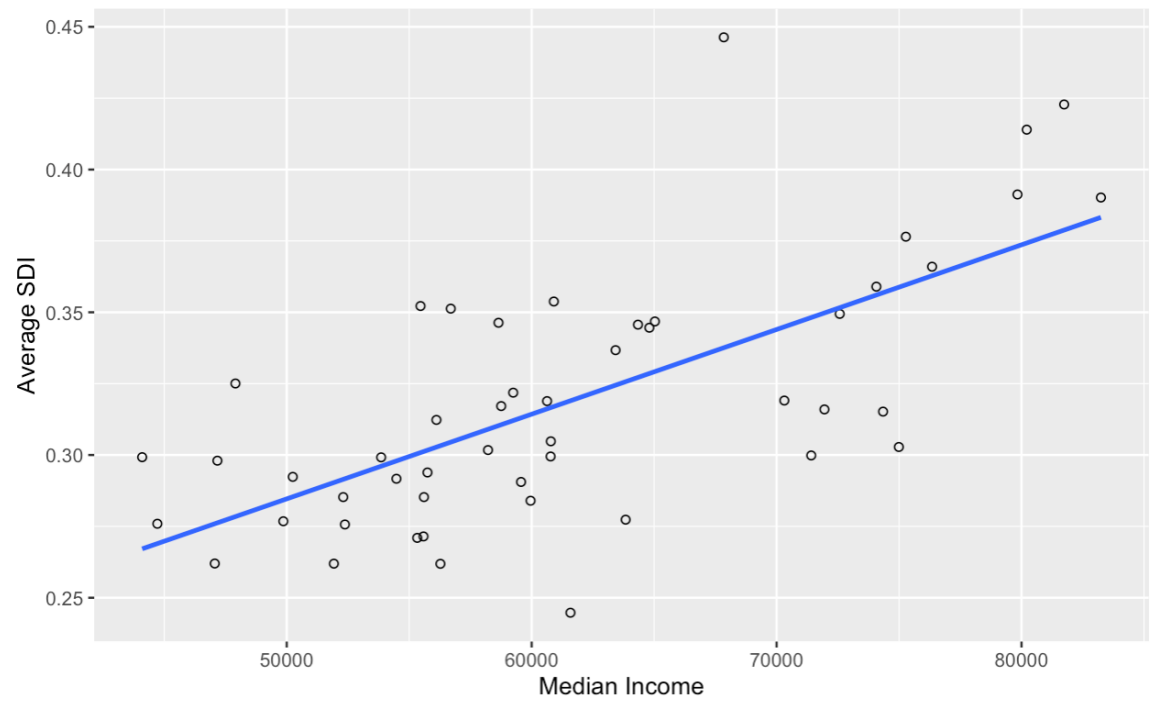

Figure 4: Relationship between state-wise median income Average SDI in the United States. The blue line indicates nature of the relationship which is positive

\section{THE “PARTISAN" HYPOTHESIS}

The most significant relationship of the partisan hypothesis is between the change in a Governor's approval rating from Q4 2019 to July 2020 and social distancing behaviour. States where governors had positive changes in their approval rating engaged in more social distancing than states where approval ratings dropped or stayed even (Figure 5). 


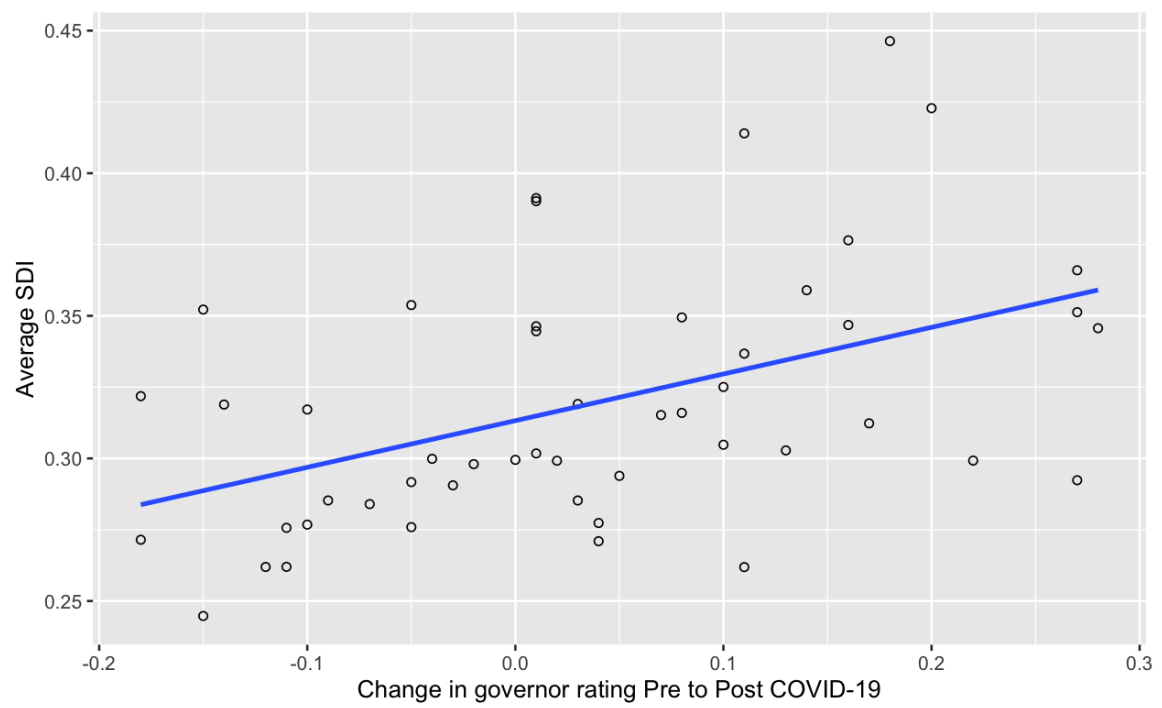

Figure 5: Relationship between change in approval ratings for state governor and Average SDI for every state in the United States. The blue line indicates nature of the relationship which is positive

In addition to this significant result, there are other clear relationships between political leaning and social distancing behaviour in the data. There is an apparent, though not statistically significant, negative relationship between the proportion of votes for Trump in 2016 in a state and social distancing behaviour. States with higher proportions of Trump voters in their population engaged in less social distancing than states with lower proportions of Trump voters (Figure 6). The President's margin of victory in 2016 is not far from significance in the model, indicating an interesting sub-group analysis: States the President won a higher proportion of votes in social distanced less often.

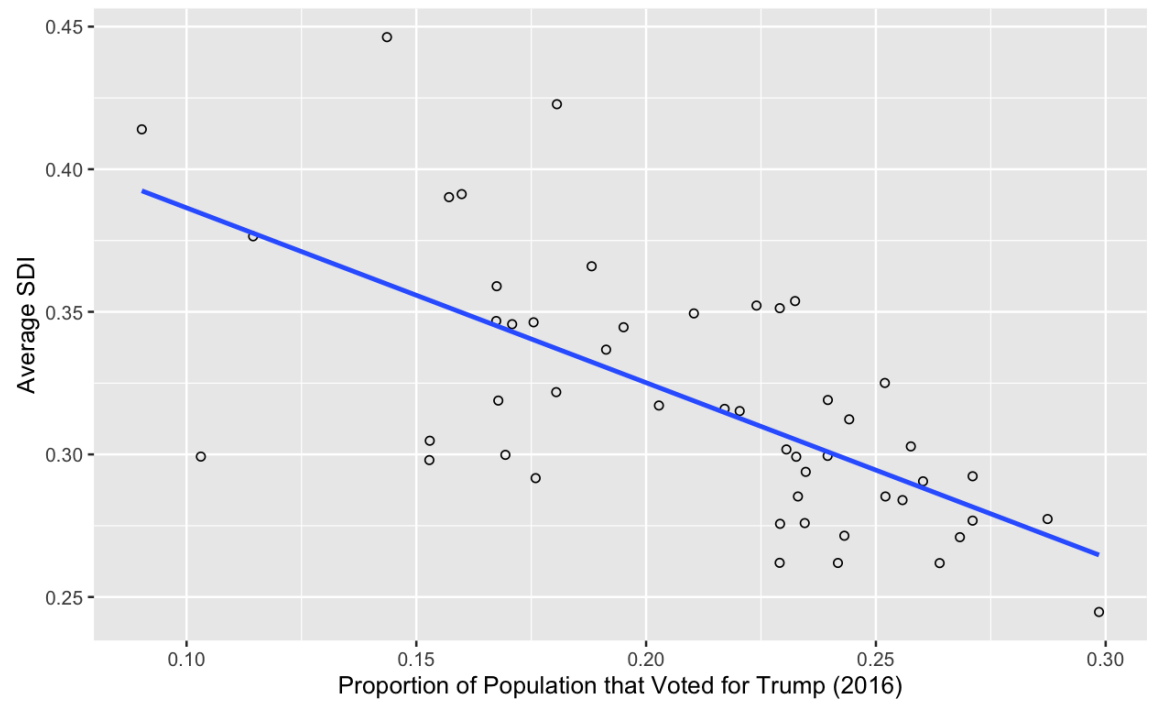

Figure 6: Relationship between proportion of Trump voters in 2016 and Average SDI for every state in the United States. The blue line indicates nature of the relationship which is negative.

Governors also appeared to play an influential and partisan role. There is a clear relationship between the party of a state's governor and social distancing behaviour. It was observed that states with Democratic governors engaged in more social distancing on average as compared to states with Republican governors (Figure 7).

This result follows the partisan logic that has defined the timing of state social distancing policies, as Republican governors were later to implement executive stayat-home-orders. The result could be a function of this difference in policy or due to differing messages from governors, as we examine further in the case studies. 


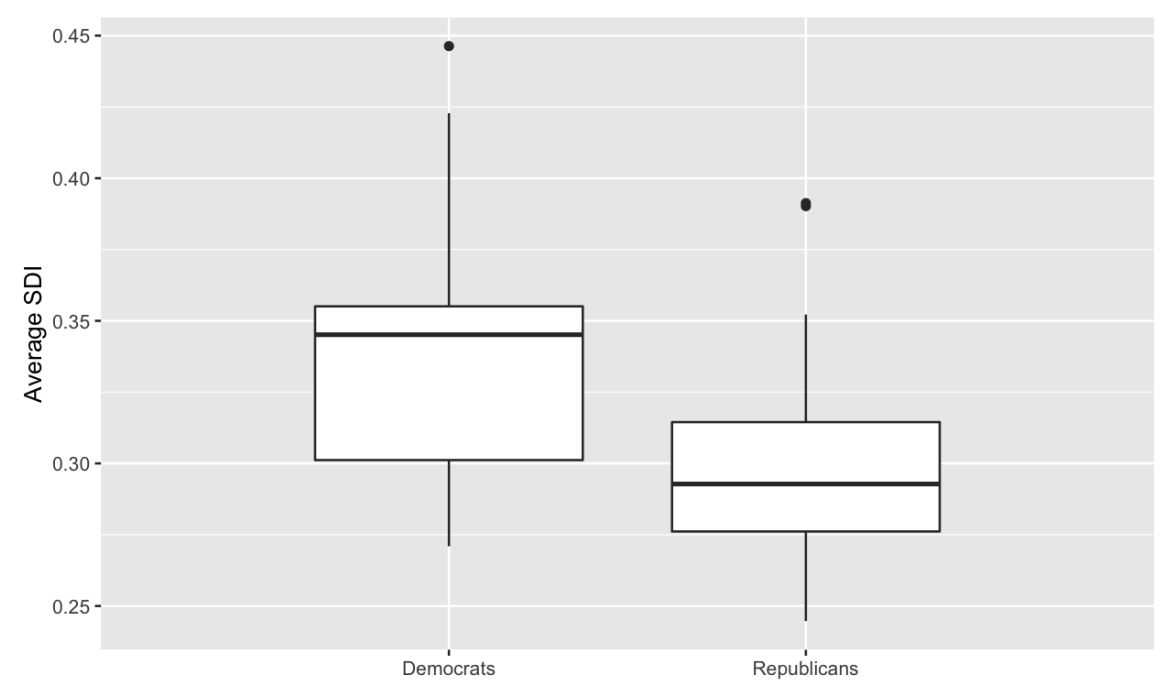

Figure 7: Comparison of Average Social Distancing Index based on party of the state governors. Note that states with Democrat governors on average social distanced more as compared to Republican states.

\subsection{Case Studies}

\subsubsection{California}

To better understand how national influences on social distancing behaviour manifested within states, we decided to perform two case studies on Texas and California. In addition to being the largest states in the Union, Texas and California sit squarely on opposite sides of the political spectrum. The responses of California Governor Gavin Newsom and Texas Governor Bill Abbot reflected partisan differences in policy decisions observed at the national level.

The Granger Causality test provides statistical evidence to support the hypothesis that social distancing behaviour affects the number of reported COVID-19 cases in California. This conclusion aligns with epidemiological research that shows a clear connection between social distancing and the spread of pandemics (Wilder-Smith and Freedman, 2020).
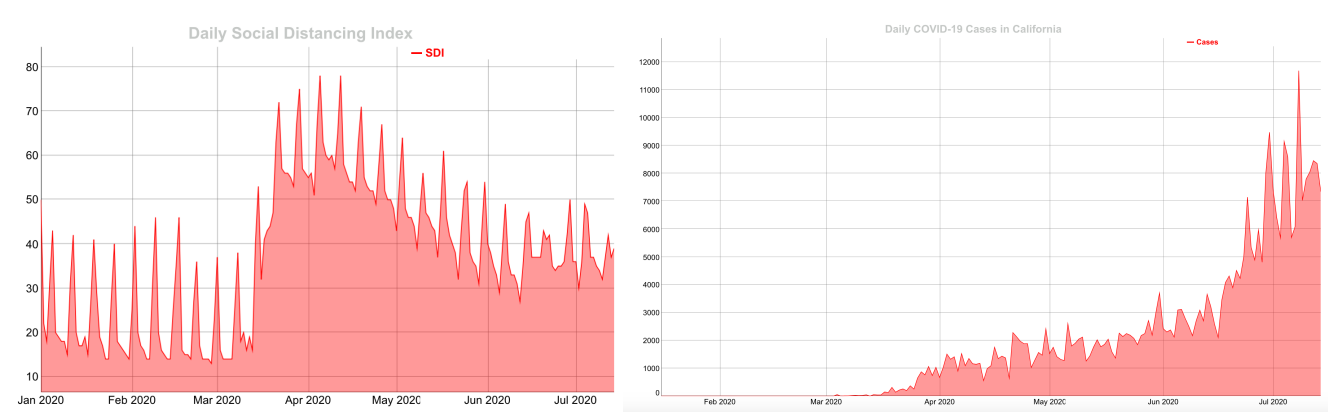

Figure 8: Time series graphs of SDI (left) and Cases(right) in California.

Additionally, the Granger Causality test provides evidence against the null hypothesis, that the reported number of cases does not affect the state's measured SDI. Succinctly, as case numbers went up, social distancing followed (Figure 8). This result speaks to California's specific experience with COVID-19, and as the next case study will explore, this relationship is not present in Texas. Our explanation for this result lies in California's policy and case number trends, which form a clear narrative of the state's COVID-19 experience.

The devastating international outbreaks of COVID-19 in Wuhan, China, Southern Italy, and Spain warned epidemiologists and California policy-makers that to contain the spread of the virus, actions must be taken to encourage social distancing. 
As a direct consequence, on March 16th, many of California's more populous Bay Area counties (Alameda, Contra Costa, Marin, San Francisco, San Mateo, and Santa Clara counties, along with the city of Berkeley) employed some of the first county-wide stay at home orders in the country (Secon, 2020). Following suit three days later, Governor Newsom ordered the country's first stay-at-home order on March 19th. The SDI data from this time frame indicates this early action helped contain the spread of COVID-19 in California, in stark contrast to other parts of the country at the time. When New York City was becoming a global pandemic epicenter, California had just around 10\% of New York State's case numbers (Lopez, 2020). This was true despite California also being home to large and dense urban population centers like Los Angeles and the Greater Bay Area.

Cases stayed relatively low through April and May in California, and the state government began to move forward with a reopening plan. On May 9th, Newsom ordered the first steps to reopening, allowing for some retail stores to open at limited capacity, along with businesses deemed essential that were closed by the original order. Cases experienced a small uptick but stayed relatively low compared to the eastern seaboard, and the state decided to push forward in reopening. The plan released on June 7 th allowed counties to begin opening up en masse - including bars, gyms, places of worship, and beaches (Secon, 2020). As Newsom's reopening policy went into effect in early June, a sharp increase in reported cases is observed.

This is where the outbreak in California began, but this increase in cases is coupled with a change in the SDI trend. As cases rose, residents began to social distance more (Figure 8).

The increase in reported case numbers leading to an increase in measured SDI can be explained by a few different factors. Primarily, California experienced their outbreak months after the surges in other states such as New York, New Jersey, and Louisiana. Therefore, California residents were aware of the dangers of failing to social distance, which could have contributed to the increase in social distancing behaviour when cases began to rise in June. California residents have approved highly of Governor Newsom's COVID response, indicating trust in the state government's handling of the pandemic. Polling data show that amongst U.S governors, Newsom saw the biggest positive change in pre-COVID-19 approval ratings to approval of his response to COVID-19, going from $42 \%$ to $83 \%$ (Mehta, 2020).

Finally, California has the seventh highest annual median income in the country, sitting at $\$ 75,277$ a year (U.S. Census Bureau). This likely also played a role in California's social distancing behaviour, considering the positive relationship between median income and social distancing. We conclude that a combination of these three factors - knowledge of past outbreaks, high trust in state government, and high median income induced California residents to social distance when case numbers began to rise in early June.

\subsubsection{Texas}

Texas has followed a different trajectory with respect to the spread of COVID-19 than other parts of the nation. In early April, while states like New York and Michigan were facing enormous increases in cases, Texas' incidence was relatively low and new cases were not climbing with the same rapidity as other regions. This persisted even as the SDI data from the same period showed little social distancing behavior.

A formal stay-at-home order was issued by Governor Greg Abbott on March 31, 2020, which coincides with an upward trend in social distancing amongst Texans that continued until April 17, 2020, when Abbott announced initial steps to reopen businesses. This first phase of loosening restrictions occurs at the peak of the SDI data, a clear inflection point in the behavioral trend that moved in tandem with a notable increase in cases. On April 23, just six days later, 21,944 Texans had tested positive for the coronavirus, which was a 4,573 case increase from the original reopening announcement. The most significant uptick occurred later in the summer 
after Abbott released an executive order on June 3rd allowing virtually all businesses to operate at 50\% capacity or greater. On June 1oth, Texas hit a new daily high in the number of COVID cases, with over 2,500 new cases reported in a single day (Figure 9).
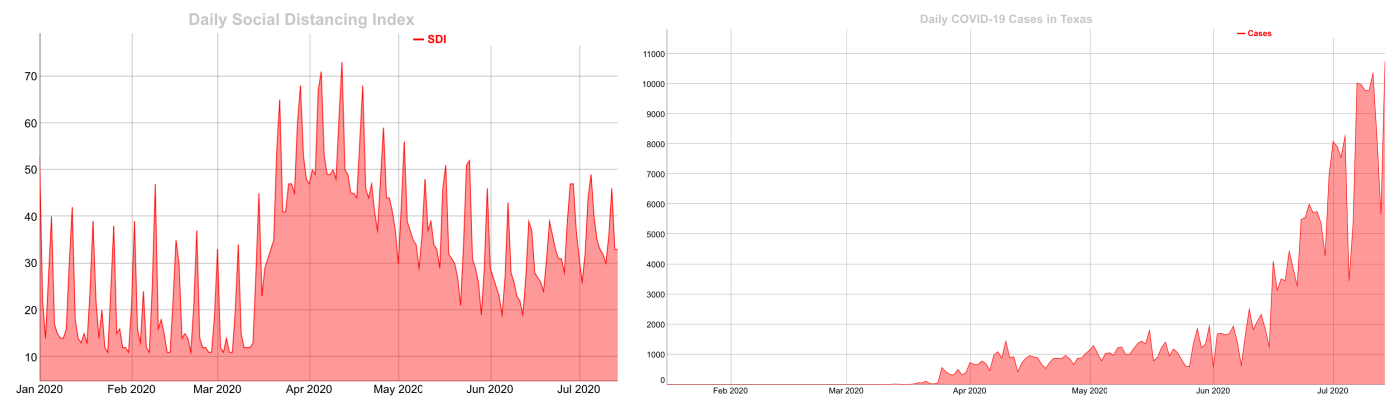

Figure 9: Time series graphs of SDI (left) and Cases(right) in Texas.

Cases continued to increase rapidly, and on the day that the overall COVID-19 death toll surpassed 2,00o, Governor Abbott told Texans that "there is no reason to be alarmed" about the growing numbers. Abbott has consistently offered unwavering reassurance throughout the pandemic, often framing social distancing as an elective practice with ultimately harmful consequences.

Our statistical analysis supports the fear hypothesis in Texas, as the data show low SDI numbers in May followed by increases in social distancing behaviour after deaths spiked in mid-June. The average SDI during the mid-July peak period is still much lower than the April pre-reopening high point. Our analysis did not find evidence of a partisan influence in individual decision-making, but the influence of a Republican governor may have contributed to this behavior throughout the state, through policy or rhetoric.

The statements, directives, and attitudes of public officials, such as the governor, serve as a guide to the public during a crisis. During the $2009 \mathrm{H} \mathrm{H}_{\mathrm{N}}$ pandemic, effective communication was central to Americans' ability to manage uncertainty (Quinn et. al, 2013). Further, official responses to pandemics encourage and validate certain behavior - when President Obama publicly shared his daughters were vaccinated in 2009, there was a powerful positive and bipartisan impact on vaccination decisions (Quinn et. al, 2013).

As such, it seems reasonable to argue that Abbott's presentation of social distancing policy would affect social distancing behaviour. Another example of Abbot's elective, skeptical framing of social distancing was his reluctance to refer to the March 31 shelter-in-place mandate as a "Stay-at-Home" order - a phrase adopted by other states without hesitation (Abbott's order is titled "relating to statewide continuity of essential services and activities during the COVID-19 disaster"). Messages from other public officials, such as the aforementioned claim made by Lieutenant Governor Dan Patrick, work to reduce COVID-related fear amongst some communities but fail to provide adequate supporting evidence. This set of policy actions and rhetoric could very well have contributed to low SDI averages in Texas while cases and deaths were escalating in June and July.

With regard to the income hypothesis, the demographics of Texas give insight to the relationship between income and social distancing. The median income in Texas trails behind that of California, with the average household making \$59,570 annually. This could have contributed to the relative lack of social distancing seen early on in Texas' COVID-19 experience. The majority of essential, low-income workers in Texas are also people of color, who have been disproportionately affected by the pandemic. Hispanic Texans account for $48.8 \%$ of coronavirus deaths but compose only $39.6 \%$ of the total population, and make up $36 \%$ of people living in poverty in Texas (Platoff and Astudillo, 2020). The relationships between race, income level, and COVID incidence are hard to overlook in this context, and the 
data suggest a need to examine the sources of disparities present within Texas when considering social distancing as a tool for outbreak mitigation.

\section{DISCUSSION}

The Social Distancing Index offers information on the behaviour of most Americans by using daily cell phone geolocation data. It makes population-level behavioural analysis possible by representing a massive number of people, divided into units of analysis that contain meaningful differences in political beliefs, public policy, economic environments, and outbreak severity. The data we use reliably measure the actions of at least eight out of ten Americans (Pew Research Center, 2018), over a period of six and a half months, across all fifty states.

Our research shows statistically significant evidence for the fear hypothesis below $\mathrm{p}<$.0001 (Table 2). Total deaths have the most significant relationship with SDI, which is positive. In states with the relatively largest elderly and therefore atrisk populations, social distancing behaviour is also more prevalent. The evidence points specifically to an influential fear of death, less so of falling ill. This can be seen further in the differing relationships between cases and social distancing in California and Texas. While more cases led to more social distancing in California, they did not in Texas. When deaths rose in Texas in late June, social distancing eventually followed - an example of the national relationship between total deaths and SDI. This suggests that an abstract fear of COVID-19 is less influential than a more localized fear of dying from COVID-19.

The income hypothesis has convincing results as seen in both the relationship between median income and SDI, and the relationship between the size of low income brackets and SDI. The proportion of a state's population in three of the four lowest-income brackets has a statistically significant negative relationship with SDI - states with relatively more low-income individuals (in the annual income brackets USD \$10,000 - 14,999, 15,000 - 24,999, and 35,000 - 49,000) engaged in less social distancing. The relationship between median income and SDI also supports the income hypothesis, as there exists a positive relationship, suggesting the trend is consistent throughout the state median income spectrum. Considering the "essential work" causal mechanism and these significant results, the evidence offers strong support to the income hypothesis.

Evidence for the partisan hypothesis is slightly less significant than for the income and fear hypotheses, yet still informative. The relationship between the proportion of Trump voters in 2016 in a state and social distancing behaviour could suggest an influence of partisan leaning on behaviour at the population level. A similar relationship exists between social distancing behavior in a state and the party of its governor - states with Republican governors social distanced less often than states with Democratic governors. These partisan differences are likely due to polarized rhetoric and policy employed by governors of each party, as seen in the case studies and Baccini and Brodeur (2020).

Governors' approval ratings had a significant and positive relationship with social distancing behaviour. This includes Republican governors in typically Democratic states who enacted social distancing measures, such as Larry Hogan in Maryland and Charlie Baker in Massachusetts. Polarization has not conclusively passed social distancing as a test of behavioural impact, but there is evidence to suggest that more support for the President led to less social distancing at the population level. Considering the potentially dire consequences of failing to social distance, this trend speaks to the strength of partisanship and polarization - both may be extending outwards, to influence more than what lies within narrow political definitions. There is opportunity for further research performed across longer periods to enable more precise analyses of what has caused the apparent partisan influence on social distancing behaviour. 
A significant limitation of this study is failing to perform quantitative analysis on the isolated impact of social distancing policy stringency across the units of analysis. Even though robust measurements for policy stringency that take multiple factors into consideration like the Oxford Stringency Index exist (Hale et. al 2020), reopenings are still being negotiated, and reliable measures of stringency change on a regular basis. As a result, measuring the impact of public policy on social distancing behaviour through standardized stringency measures was not within the scope of our research, and may be more amenable to investigation with a larger sample of policies and SDI as data continue to accumulate. There is opportunity for future work to explore these relationships in more detail. It is our view that this would be done best in greater hindsight, with careful attention to the exact periods in which policies were in place in different states, state government reopening zones, and localities. Another limitation to be noted is that the polling data we use to calculate change in governor approval ratings have margins of error, and come from two organizations with unique polling methodologies. Therefore, a degree of uncertainty exists in our interpretation of that result.

\section{CONCLUSIONS}

It is evident that deaths in a state have a powerful impact on social distancing decisions. It is less clear that cases in states with fewer deaths have a similar impact, possibly because case numbers can command less attention than the death count. Arguably proven by the Spanish Flu over a century ago, social distancing works. Our statistical analysis provides additional evidence that more social distancing leads to fewer cases. Income has an important relationship with social distancing behaviour, that sheds light on the challenge faced by essential workers - in order to keep critical supply chains running, lower income individuals and their communities are exposed to a greater risk of infection by less social distancing. We see the observations regarding partisanship and its relationship with social distancing as a contribution to the growing basis of evidence demonstrating political polarization to be a central facet of American public life. Though the evidence is not sufficient to suggest causality, the relationships between the proportion of Trump voters in a state and social distancing behaviour, and between a governor's party and social distancing behaviour, indicate that partisanship can impact decision-making even during a pandemic.

\section{ACKNOWLEDGEMENTS}

We thank the University of Toronto's Office of the Vice-President, International; the University of Toronto Mississauga; the University of Toronto Scarborough; the Faculty of Arts and Science, the Faculty of Applied Science and Engineering, the Rotman School of Management, OISE, and the Centre for International Experience. This study was conducted with their support through the University's COVID-19 Student Engagement Award. We also specifically thank the University of Toronto's Vice-President, International Dr. Joseph Wong, for dedicating his time to bringing students together to perform meaningful work; Dr. Teresa Kramarz, Director of the Munk One Foundational program and Codirector of the Global Environmental Governance Lab, for always engaging students, teaching two authors the research skills used in this study, and for encouraging us to realize this project; Julia Kulik, Research Officer at the Office of the Vice-President, International, for her consistent communication and support throughout the project; and Connie Tang, Assistant Director for Research and Outreach at the Maryland Transportation Institute, for fulfilling our data request. Finally, the lead author thanks the authors of the COVID Comparative Project, for the conversations that helped form the inspiration and perspective for this study; and Dr. Dan Walker, Managing Director at the University of Maryland's Department of Civil and Environmental Engineering, for sharing the Social Distancing Index and sparking the idea. 
- Abramowitz, A. (2010). The Disappearing Center: Engaged Citizens, Polarization, and American Democracy. Yale University Press.

- Astudillo, E. P. and C. (2020, July 30). Across Texas and the nation, the novel coronavirus is deadlier for people of color. The Texas Tribune. https://www. texastribune.org/2020/07/30/texas - coronavi rus - deaths/

- Baker, P. (2020, April 12). Trump Lashes Out at Fauci Amid Criticism of Slow Virus Response. The New York Times. https://www. nytimes. com/2020/04/ 12/us/politics/trump - fauci - coronavirus . html

- Beckett, L. (2020, March 24). Older people would rather die than let Covid-19 harm US economy - Texas official. The Guardian. Link to Source

- Bellhaus, R. (2020, October 15). A Demoralized CDC Grapples With White House Meddling and Its Own Mistakes. Wall Street Journal. Link to Source

- Belluz, J. (2018, February 23). Trump vs. "disease X." Vox. Link to Source

- Cathey, L. (2020, July 15). Tracking Trump and Fauci's tense relationship. ABC News. Retrieved November 3, 2020, from https://abcnews.go.com/ Politics/tracking-trump-faucis-tense-relationship/story?id=71771514

- CDC. (2020, February 11). Coronavirus Disease 2019 (COVID-19). Centers for Disease Control and Prevention. https : //www. cdc.gov/coronavi rus/2019-ncov/ need-extra-precautions/older-adults. html

- City News Service. (May 9, 2020). Hundreds Protest COVID-19 Restrictions in Huntington Beach - NBC Los Angeles. Retrieved September 4, 2020, from Link to Source Accessed 4 Sept. 2020.

- Eder, S., Fountain, H., Keller, M. H., Xiao, M., Stevenson, A. (2020, April 15). 430,00o People Have Traveled From China to U.S. Since Coronavirus Surfaced. The New York Times. https://www. nytimes.com/2020/04/04/us/ coronavirus - china - travel - restrictions. html

- Exec. Order 13910 of Mar 23, 2020, 50 U.S.C Sec. 4512 (2018) Link to Source

- Guidotti, E., Ardia, D. (2020). COVID-19 Data Hub. Journal of Open Source Software, 5(51), 2376. doi:10.21105/joss. 02376

- Haberman, M., Sanger, D. E. (2020, March 23). Trump Says Coronavirus Cure Cannot 'Be Worse Than the Problem Itself.' The New York Times. https:// www. nytimes. com/2020/03/23/us/politics/trump-coronavirus - restrictions. html

- Hale, Thomas, Noam Angrist, Emily Cameron-Blake, Laura Hallas, Beatriz Kira, Saptarshi Majumdar, Anna Petherick, Toby Phillips, Helen Tatlow, Samuel Webster (2020). Oxford COVID-19 Government Response Tracker, Blavatnik School of Government.

- Han, H. (2011). The Disappearing Center: Engaged Citizens, Polarization, and American Democracy. Public Opinion Quarterly, 75(4), 812-813. doi: 10. 1093/poq/nfro42.

- Johnson, Z. (2020, July 23). German Pandemic Efficiency: Fiscal Capacity, Logistical Coordination, and Infrastructure. Munk School of Global Affairs and Public Policy. Link to Source

- Kavi, A. (2020, July 22). Virus Surge Brings Calls for Trump to Invoke Defense Production Act. The New York Times. https://www. nytimes.com/2020/07/ 22/us/politics/coronavirus-defense- production-act.html

- Kliesen, K. L. (2003). The 2001 Recession: How Was It Different and What Developments May Have Caused It? 16.

- Lopez, G. (2020, July 6). How California went from a coronavirus success story to a worrying new hot spot. Vox. https://www.vox.com/future-perfect/ 2020/7/6/21308351/cali fornia-coronavirus - pandemic - covid - outbreak

- Mehta, D. (2020, April 10). Most Americans Like How Their Governor Is Handling The Coronavirus Outbreak. FiveThirtyEight. Link to Source

- Nguyen, T. (2020, April 4). The Trump administration has made getting necessary medical equipment difficult. Vox. https://www.vox.com/2020/4/4/ 21208122/ppe-distribution-trump-administ ration-states 
- Mueller, J., Stewart, M. G. (2012). The Terrorism Delusion: America's Overwrought Response to September 11. International Security, 37(1), 81-110. https://www. mitpressjournals.org/doi/abs/10.1162/ISEC_a_00089

- Perry, G. L. (2001, November 30). Forecasting the Economy and Policy After 9/11. Brookings. Link to Source

- Staff, R. (2020, March 26). Partly false claim: Trump fired entire pandemic response team in 2018. Reuters. Link to Source

- Pew Research Center. (n.d.). Demographics of Mobile Device Ownership and Adoption in the United States. Pew Research Center: Internet, Science Tech. Retrieved November 2, 2020, from https://www. pewresearch.org/internet/ fact-sheet/mobile/. Accessed 2 Nov. 2020.

- Public Health Service Act of 1944, Pub. L. No. 264, 42 U.S. Code (2008). Link to Source

- New York Times. (2017, August 9). Presidential Election Results: Donald J. Trump Wins. The New York Times. https://www. nytimes.com/elections/ 2016/results/president. Accessed 4 Sept. 2020.

- Quinn, S. C., Parmer, J., Freimuth, V. S., Hilyard, K. M., Musa, D., Kim, K. H. (2013). Exploring Communication, Trust in Government, and Vaccination Intention Later in the 2009 HiNi Pandemic: Results of a National Survey. Biosecurity and Bioterrorism: Biodefense Strategy, Practice, and Science, 11(2), 96-106. doi:10.1089/bsp.2012.0048.

- Shambaugh, R. N., Jimmy O'Donnell, and Jay. (2020, June 4). Examining Options to Boost Essential Worker Wages during the Pandemic. Brookings. Link to Source

- US Census Bureau (2019). Population Estimates Continue to Show the Nation's Growth Is Slowing. The United States Census Bureau. Retrieved September 4, 2020, from https://www. census.gov/news room/press - releases/2019/ popest-nation. html

- Wilder-Smith, A., Freedman, D. O. (2020). Isolation, quarantine, social distancing and community containment: Pivotal role for old-style public health measures in the novel coronavirus (2019-nCoV) outbreak. Journal of Travel Medicine, 27(2). https://doi.org/10.1093/jtm/taaao20 doi : 10.1093/jtm/taaa020.

- Zhang, L., Ghader, S., Pack, M. L., Xiong, C., Darzi, A., Yang, M., Sun, Q., Kabiri, A., Hu, S. (2020). AN INTERACTIVE COVID-19 MOBILITY IMPACT AND SOCIAL DISTANCING ANALYSIS PLATFORM. MedRxiv, 2020.04.29.20085472. https://doi.org/10.1101/2020.04.29.20085472

\section{DATASETS}

- Social Distancing Index : Zhang, Lei, et al. "AN INTERACTIVE COVID-19 MOBILITY IMPACT AND SOCIAL DISTANCING ANALYSIS PLATFORM." MedRxiv, Cold Spring Harbor Laboratory Press, May 2020, p. 2020.04.29.20085472. www. medrxiv. org, doi:10.1101/2020.04.29.20085472.

- Approval ratings: Lazer, D., Quintana, A., Ognyanova, K., Baum, M., A., Volpe, J. D., Druckman, J., Perlis, R. H., Santillana, M., Chwe, H., Simonson, M. (2020). Update on the Approval of Executive Performance During COVID-19 (Report of July 29, 2020 v.2 No. 6; Executive Performance Approval). The COVID-19 Consortium for Understanding the Public's Policy Preferences Across States. ;

- Governor Rankings Q4 2019. (2020). Morning Consult. Retrieved August 1, 2020, from https://morningconsult. com/governor-rankings/

- 2016 Election Results: New York Times. "Presidential Election Results: Donald J. Trump Wins." The New York Times, 9 Aug. 2017. NYTimes.com, https://www. nytimes . com/elections/2016/results/president.

- Income Data: US Census Bureau, American Communities Survey. Income in the Past 12 Months in 2018 Inflation-Adjusted Dollars (Table ID: S1901). Accessed 26 Aug. 2020.

- COVID-19 Dataset: Guidotti, Emanuele, and David Ardia. "COVID-19 Data Hub." Journal of Open Source Software, vol. 5, no. 51, July 2020, p. 2376. joss.theoj.org, doi:10.21105/joss. 02376 


\section{ABOUT THE STUDENT AUTHORS}

All authors will be completing their undergraduate education in 2022 except Jordan Tirico, who will graduate in 2023. Liam Keating will be graduating with an Honors BA, Specialist in Political Science; Nayan Saxena with an Honors BSc, majors in Statistics and Mathematics; Emma Cooper with a BA, majors in Economics and Pub- lic Policy; Jordan Tirico with a BS, Major in Engineering - Atmosphere/Energy; Daniel Khain with a BS, majors in Computer Science and Honors Mathematics; and Daphne Imahori with an Honors BSc, majors in Global Health, Statistics, and Bioethics.

The politicization of social distancing policy has formed a major public debate during COVID-19 in the United States, coinciding with similar debates over mask- wearing and skepticism towards vaccine inoculation. It is reasonable to assume that the politicization of social distancing would impact how often those on each side of the partisan divide practice social distancing. But social distancing is a behaviour that involves daily, individual, and complex risk assessments, likely in- volving more considerations than just the political. The outcome of these risk as- sessments, which is Americans' collective social distancing behaviour, has been mea- sured by the Maryland Transportation Institute's Social Distancing Index (SDI). We use the SDI to examine whether differences in social distancing behaviour are due to differences in demographic, income, political, or pandemic variables, across all fifty states. The evidence show statistically significant and informative relationships between variables in each of these sets and social distancing behaviour. Total deaths from COVID-19 in a state and the proportion of its population older than sixty-five had especially significant impacts, offering strong evidence to support the first of three hypotheses we examine - that fear of COVID-19 plays an important role in guiding Americans' social distancing behaviour.

\section{APPENDIX}

\subsection{Graphs of Predicted SDI (VAR Models)}

TEXAS

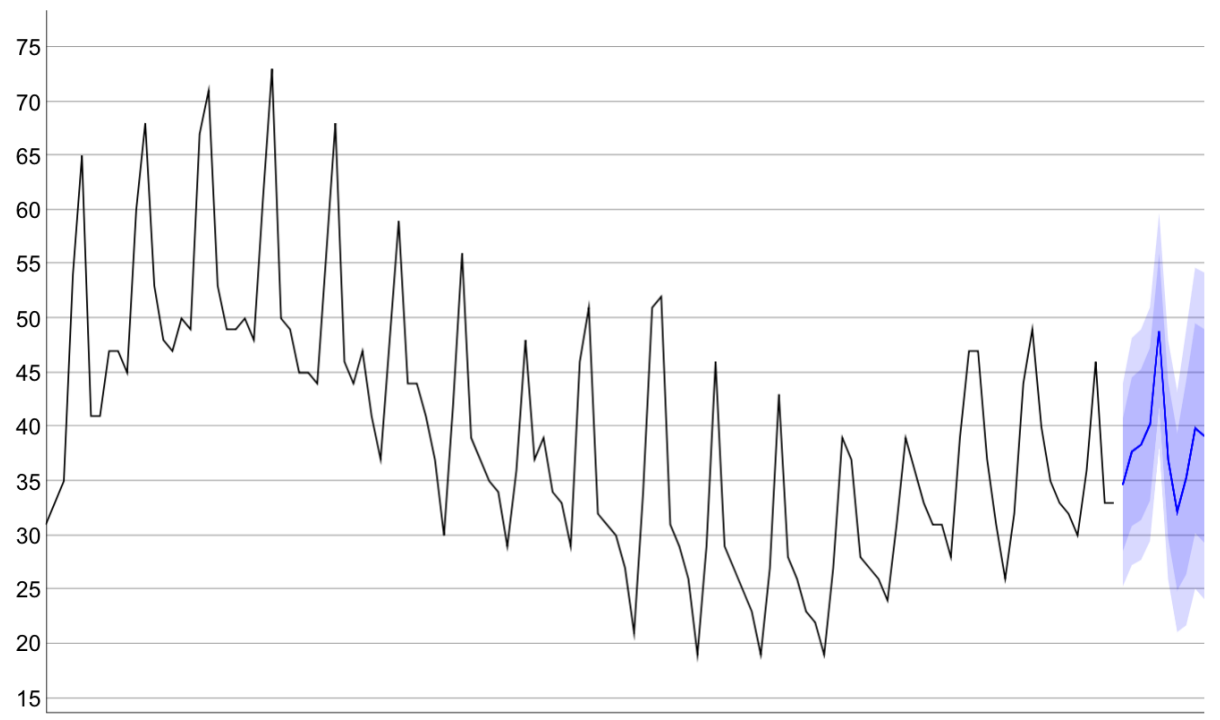


APPENDIX

17

CALIFORNIA

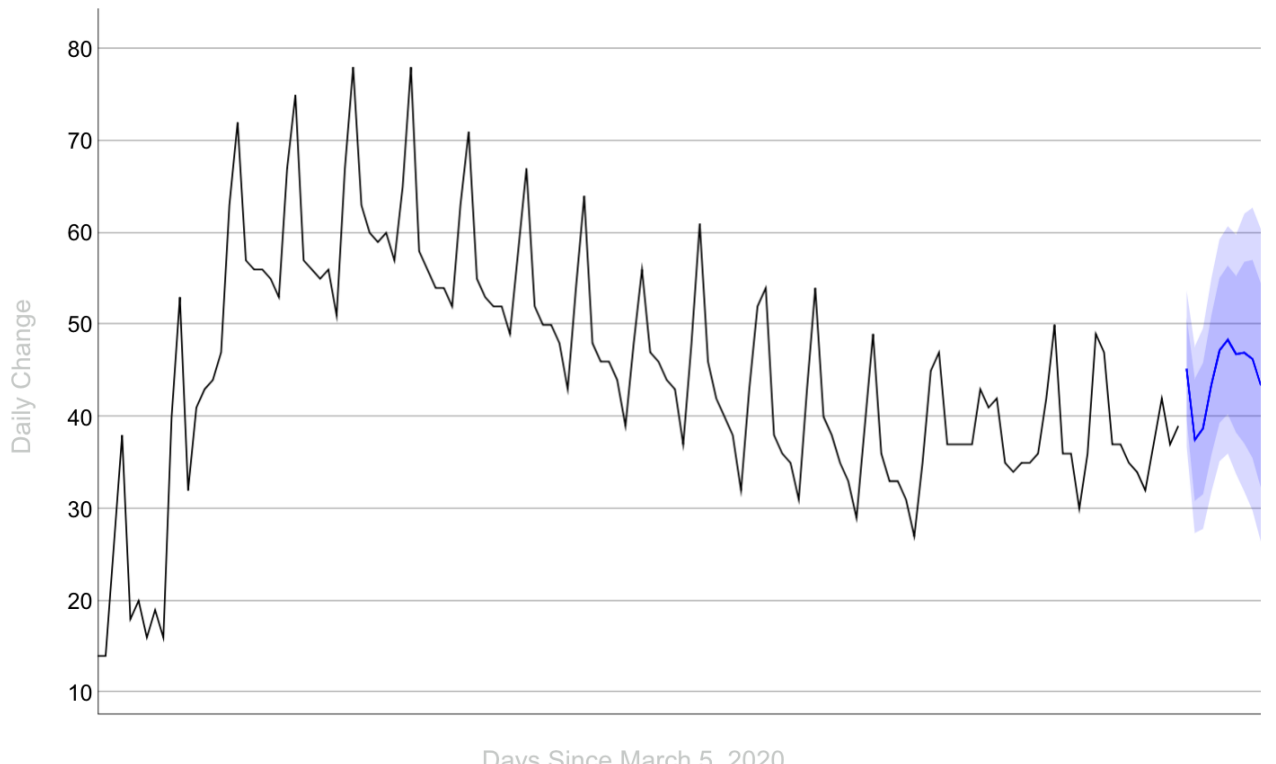

Days Since March 5, 2020 
11.2 Model Diagnostic Plot
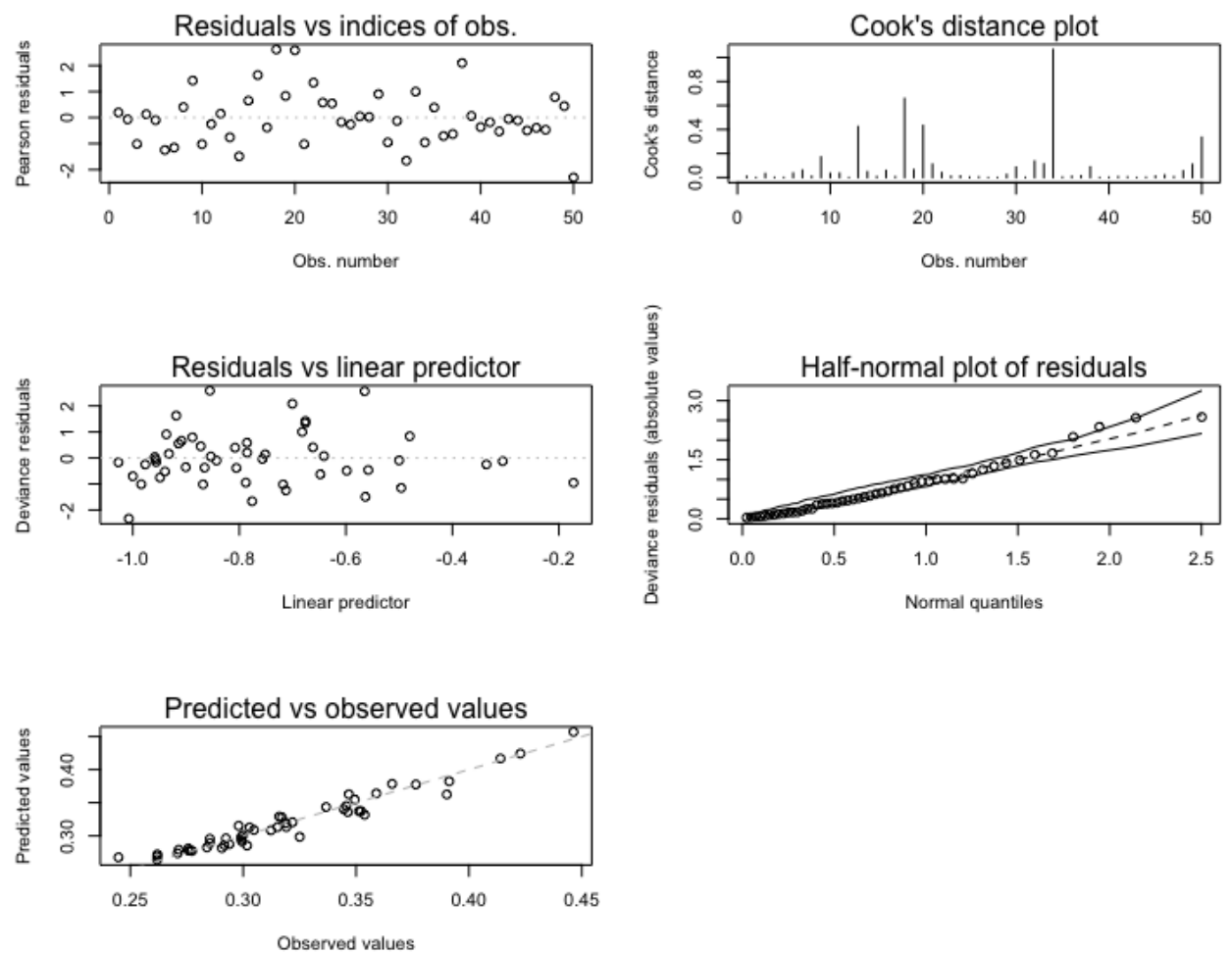

Figure 10: Model diagnostic plots for the Beta Regression model with summary shown in Table 2. It should be noted that the residual plots show heteroscedasticity and the normal plot shows very less deviation from normality - therefore the model reasonably explains the variation in the SDI response variable. 